\title{
OS DIREITOS HUMANOS COMO EXIGÊNCIAS E REIVINDICAÇÕES MÚTUAS
}

HUMAN RIGHTS AS MUTUAL CLAIMS AND REQUIREMENTS

LOS DERECHOS HUMANOS COMO EXIGENCIAS Y REIVINDICACIONES MUTUAS

André Luiz Olivier da Silva ${ }^{1}$

1 Professor do Curso de Graduação em Direito da Universidade do Vale do Rio dos Sinos UNISINOS, São Leopoldo, Rio Grande do Sul, Brasil. Atualmente, é Coordenador do Curso de Graduação em Direito da UNISINOS, bem como Advogado e Doutor em Filosofia pela mesma instituição. Endereço eletrônico: aolivierdasilva@yahoo.com.br. 
Resumo: O artigo aborda o significado dos direitos a partir da metáfora do título ao portador presente na dogmática jurídica, segundo a qual os direitos são compreendidos formalmente como um título concedido dentro de um sistema legal. A partir de uma metodologia descritiva do fenômeno da enunciação de proposições como " $\mathrm{X}$ possui um direito em relação a $\mathrm{Y}^{\prime}$, a presente pesquisa indaga se se pode exigir direitos mesmo sem a posse de um título. O seu objetivo é apresentar um contraponto à visão dogmática dos direitos ao mostrar que a linguagem dos direitos humanos nem sempre pode ser explicada por propriedades formais, pois alguns desses direitos são exigidos e reivindicados mesmo sem a posse de um título autorizado por lei. A hipótese que se quer confirmar ao final do presente texto é que esses direitos são usados linguisticamente para reivindicar e satisfazer exigências que não se limitam à esfera das obrigações jurídicas.

Palavras-chave: Direitos. Títulos. Exigências. Direitos Humanos.

Abstract: The article discusses the significance of rights based on the metaphor of the entitlement holder present in judicial dogma, whereby rights are formally understood as a title granted within a legal system. Based on a descriptive methodology of the phenomenon of enunciation of propositions such as " $X$ has a right relative to $Y^{\prime \prime}$, this research explores whether we can demand ownership rights even without an entitlement. Its goal is to present a counterpoint to the dogmatic view, by showing that the language of human rights cannot always be explained by formal properties because some of these rights are required and claimed even without the possession of an entitlement authorized by law. The hypothesis we hope to confirm at the end of this text is that these rights are used linguistically to claim and meet requirements that are not limited to the sphere of legal obligations.

Keywords: Rights. Entitlements. Claims. Human Rights.

Resumen: El artículo aborda el significado de los derechos a 
partir de la metáfora del título al portador presente en la dogmática jurídica, según la cual los derechos son comprendidos formalmente como un título concedido dentro de un sistema legal. A partir de una metodología descriptiva del fenómeno de la enunciación de proposiciones como "X posee un derecho en relación a $\mathrm{Y}^{\prime \prime}$, la presente investigación indaga si se pueden exigir derechos aun sin la posesión de un título. Su objetivo es presentar un contrapunto a la visión dogmática de los derechos al mostrar que el lenguaje de los derechos humanos no siempre puede ser explicado por propiedades formales, pues algunos de estos derechos son exigidos y reivindicados aun sin la posesión de un título autorizado por ley. La hipótesis que se quiere confirmar al final del presente texto es que esos derechos son usados lingüísticamente para reivindicar y satisfacer exigencias que no se limitan a la esfera de las obligaciones jurídicas.

Palabras clave: Derechos. Títulos. Exigencias. Derechos Humanos.

\section{INTRODUÇÃO}

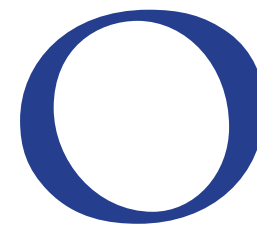

que significa ter ou possuir um direito? A dogmática jurídica tradicional julga encontrar uma solução a essa pergunta ao relacionar o significado dos direitos à metáfora de um título ao portador. Isto é, a posse de um direito depende de uma espécie de certificado, como se fosse um pedaço de papel, que habilitaria o seu portador a fazer ou possuir algo. O título seria concedido apenas dentro de um ordenamento jurídico-normativo de poder; um título que vincularia detentor e destinatário no bojo de uma relação jurídica, que colocaria o seu possuidor em posição para fazer exigências.

Ocorre que a linguagem dos direitos humanos não pode ser explicada pela mesma base normativa que a da tradição dogmática e é aqui que se apresenta o problema ao qual pretendemos resolver no presente artigo: é possível exigirmos direitos mesmo sem a posse de um título para legitimar a reivindicação que está 
sendo feita? Para tanto, pretendemos, a partir de uma abordagem descritiva do ato de se exigir direitos: (i) analisar e definir a dogmática tradicional dos direitos ao mesmo tempo em que se explica o fenômeno da reivindicação por direitos com base na metáfora do título ao portador; (ii) observar que, nas sociedades democráticas contemporâneas, algumas exigências e reivindicações são por direitos que não estão positivados em lei; e, por fim, (iii) descartar a visão dogmática dos direitos, ao mostrar que alguns deles não podem ser considerados direitos simplesmente com base no critério da legalidade do ordenamento jurídico.

Tais direitos, como os direitos humanos, são exigidos mesmo sem a posse de um título, e essa éa hipótese que queremos explorar no presente artigo. Os direitos humanos são, no fundo, exigências por direitos, exigências que independem da concessão legal de um título. Se tomarmos esses direitos como exigências, reivindicações e pretensões, veremos que, no caso de muitos direitos humanos, tomamos o termo "direitos" apenas como sinônimo de "exigências", mais especificamente "exigências por direitos" ou, quando muito, "direitos-exigidos", no sentido de claim-rights. Essas exigências nem sempre são jurídicas, de modo que a conclusão almejada pela presente pesquisa é trazer subsídios para abandonarmos a leitura formalista dos direitos como títulos ao conceber os direitos humanos simplesmente como exigências mútuas e recíprocas que pessoas reivindicam entre si.

\section{POSSUIR UM DIREITO}

Vamos tomar como ponto de partida da presente investigação a indagação sobre o significado dos direitos, tendo como base as expressões linguísticas usadas pelo senso comum para afirmar que alguém possui um direito. Só faz sentido colocar essa pergunta - o que significa ter um direito? - no bojo de proposições linguísticas completas que se refiram à sua posse dentro de frases que digam claramente que alguém possui um determinado direito a algo, conforme elucida Hart² ao destacar que "Não devemos tomar o termo 'direito', mas a frase

2 Hart segue o método de elucidação das palavras com base em Bentham: "Ele [Bentham] disse que nunca devemos tomar essas palavras sozinhas, mas sim considerar frases inteiras nas quais elas desempenham seu papel característico" (HART, Herbert Lionel Alphonsus. Definição e teoria na teoria do direito. In:

Ensaios sobre teoria do direito e filoso- 
'Você tem um direito'."3, no sentido de que o direito é sempre uma propriedade possuída por alguém. Nesse sentido, devemos indagar o significado do direito quando enunciamos proposições com as seguintes estruturas: " $X$ tem ou possui um direito $\mathrm{Q}$ " ou "X tem um direito a $\mathrm{R}^{\text {"4 }}$.

A resposta a essa indagação mostrará que um determinado indivíduo $X$ é portador de direitos e, sob essa condição, está habilitado, ou empossado, ao exercício de direitos concedidos por lei. Mostrará que só faz sentido falar em direitos quando empregados em proposições que contenham um sujeito e o ato de possuir um direito, como prossegue Hart: "Essa advertência foi em grande medida ignorada, e os juristas continuaram insistindo em palavras isoladas.. ${ }^{5}$. Os juristas continuaram a focar a análise dos direitos em uma definição restrita da palavra "direitos", sem contextualizá-lo dentro de uma relação entre pessoas. A relação dos direitos em torno das pessoas é intersubjetiva e só podemos concebêlos dentro de um jogo de vínculos entre detentor e destinatário.

\section{UM PEDAÇO DE PAPEL E A PERMISSÃO PARA FAZER OU POSSUIR}

A tradição dogmática dirá que todo direito pressupõe um título (entitlement) ${ }^{6}$ ou uma autorização ou permissão para fazer ou possuir algo, ou para que os

fia. Tradução de José Garcez Ghirardi e Lenita Maria Rimoli Esteves. Rio de Janeiro: Elsevier, 2010. Coleção Teoria e Filosofia do Direito. Ensaio 1. p. 29.). Vale a pena verificar A fragment on Government (1776), de Jeremy Bentham, obra a qual Hart se refere no ensaio Definition and theory in jurisprudence, de 1953. Conferir: BENTHAM, Jeremy. A fragment on government. Cambridge: Cambridge University Press, 1998. 128p. Conferir também: HART, Herbert Lionel Alphonsus. Definition and theory in jurisprudence. In:

Essays in Jurisprudence and Philosophy. Oxford, Clarendon Press, 1983. p. 21-48.

3 HART, Herbert Lionel Alphonsus. Definição e teoria na teoria do direito. p. 29, grifo do autor.

4 Em um célebre texto sobre a natureza dos direitos, Benn indaga: "Que tipo de asserção é dizer que $X$ tem direito a $\mathrm{R}$, e que tipo de critério deveria ser usado para que essa proposição seja verdade?" (BENN, Stanley I. RIGHTS. In: EDWARDS, Paul (editor). Encyclopedia of Philosophy. 1. ed. Tradução nossa. New York: Macmillan, 1972. v. 7. p. 195.). A propósito dessa nota de rodapé, cabe destacar que as traduções contidas neste trabalho são, em sua maioria, traduções livres do autor do presente texto, salvo exceções indicadas na bibliografia. As traduções do autor serão referidas com a expressão "tradução nossa".

5 HART, Herbert Lionel Alphonsus. Definição e teoria na teoria do direito. p. 29.

6 Dado o termo entitlement, e para padronizar e evitar maiores confusões, usaremos a palavra "título" ou até mesmo "titulação" nas referências a esse vocábulo. Por título, deve ser entendido uma autorização ou permissão para o seu portador possuir ou fazer alguma coisa ou para praticar uma ação, embora o seu sentido original retome a ideia de um certificado ou de um pedaço de papel que confere um direito a alguém, como, por exemplo, a escritura da propriedade que legitima a sua posse. 
outros façam ou deixem de fazer. Trata-se de um certificado que confere bens, vantagens e benefícios ao portador (que, no caso dos direitos humanos, é o ser humano, mas que pode ser também uma pessoa jurídica), abrindo-Ihe um leque de possibilidades para escolher em conformidade com aquilo que julga mais racional para o seu agir.

Ao possuir um direito, o portador adquire uma permissão - ou várias delas - e, em razão disso, está legalmente autorizado a fazer algo ou a usufruir algo do modo como determinar o seu querer. $O$ direito pressupõe, como dissemos, um título que autoriza, conforme o conceito "positivo" que McCloskey atribui aos direitos, ao defini-los como: "(...) títulos para fazer, ter, desfrutar ou ter feito."7. A partir desse conceito "positivo", o direito é compreendido como um "direito-para", um direito para ter ou desfrutar alguma coisa, para fazer algo positivamente no que tange à relação jurídica, um direito, muitas vezes, para se ter direitos. Afirma McCloskey:

Direitos, eu sugiro, são melhor explicados positivamente como títulos para fazer, ter, desfrutar, ou ter que fazer, e não negativamente como algo contra os outros, ou como algo que alguém deve ter. Eles são coisas que alguém tem, que alguém possui independentemente das outras pessoas e independentemente sobre o que cada um deve ser. ${ }^{8}$

Se nos permitirmos a uma metáfora, os significados da palavra "direitos", por mais diversificados que pareçam se apresentar, são mais bem entendidos sob a moldura formal de um título que se pode possuir, um título como algo que legitima e justifica o seu detentor a reivindicar direitos e a determinar o comportamento do destinatário desse direito, obrigando-o a agir de um determinado modo.

Os direitos estão transcritos em pedaço de papel, como em um recibo ou em um certificado que diz expressamente que o reivindicante possui um direito, colocando-o, então, em uma posição para reivindicar os seus direitos. Em outros casos, o sujeito pretende constituir o título e passa a pleiteá-lo como um direito

7 MCCLOSKEY, H. J. Rights. The Philosophical Quarterly, v. 15, n. 59, abr. 1965, p. 118. Tradução nossa. Disponível em: <http://www.jstor.org/stable/2218211>. Acesso em: 9 jun. 2012. Versão original: (...) are entitlements to do, have, enjoy or have done. (MCCLOSKEY, H. J. Rights. p. 118.)

8 MCCLOSKEY, H. J. Rights: some conceptual issues. Australasian Journal of Philosophy, v. 54, n. 2, p. 99, ago. 1976. Tradução nossa. Disponível em: <http://www.tandfonline. com/doi/abs/10.1080/00048407612341101>. Acesso em: 9 jun. 2012. 
para que venha a ser um direito amparado e constituído em um título. Diz Feinberg sobre a reivindicação por direitos que enunciamos ao anunciar um título:

Algumas vezes isto é feito por quem reconhecidamente detenha um direito quando notifica que então quer que lhe seja entregue o que já foi reconhecido como seu, como alguma coisa tomada de empréstimo ou que Ihe foi tomada indevidamente. Esta reivindicação é, freqüentemente, feita pela apresentação de um vale, um recibo ou um documento, isto é, um título de alguma coisa que esteja no momento em posse de outrem. Em outras ocasiões, fazer uma reivindicação é candidatar-se aos próprios títulos ou direitos, como quando um prospector de minério faz uma reivindicação de direito de pesquisa de jazida, ou quando um proprietário reivindica uma extensão de terra pertencente ao governo, ou um inventor reivindica seus direitos de patente. No primeiro tipo de caso, fazer reivindicação é exercer direitos que já se tem, apresentandose um título; no outro tipo, é candidatar-se ao próprio título, mostrandose que se satisfizeram condições específicas por uma norma para a posse do título, podendo-se, por isso, exigi-lo como devido. ${ }^{9}$

A analogia do título ajuda a explicar o significado da palavra "direito" quando empregada em expressões corriqueiras da linguagem, esclarecendo que os direitos constituem-se como autorização ou permissão, de modo que, quando se diz que temos ou possuímos um direito, estamos afirmando que alguém está autorizado e habilitado a usufruir algo ou a praticar determinada ação, ou mesmo a exigir direitos. Se essa analogia estiver correta e, de fato, usamos a palavra "direito" em um sentido análogo ao de "título", então, poderemos explicar com mais clareza o modo como empregamos essa palavra não apenas no contexto dos tribunais, das transações comerciais, da elaboração de leis, mas também no dia a dia e no modo furtivo e aleatório com o qual empregamos a linguagem dos direitos em frases como " $X$ tem o direito $Q$ " ou "X possui o direito a R".

\section{A RELAÇÃO OBRIGACIONAL ENTRE DETENTOR E DESTINATÁRIO}

Dizemos, em geral, que alguém está autorizado porque a lei lhe outorgou um direito; do contrário, não viveríamos em uma sociedade civilmente organizada; ou seríamos residentes de um reino, onde, para se ter direitos, é necessário ser 9 FEINBERG, Joel. Filosofia social. Tradução de Alzira Soares da Rocha e Helena Maria Camacho. Rio de Janeiro: Zahar, 1974. p. 99. 
amigo do rei e beneficiário dos títulos e das condecorações que ele concede a alguns de seus súditos. Trata-se, neste último caso, não mais do que um privilégio e uma regalia que somente um grupo distinto e selecionado consegue possuir, e que lembra muito os modelos políticos tradicionais da Idade Média e que de algum modo se perpetuaram ao longo da Modernidade.

O direito como título, ou a "visão dos direitos como títulos"10, conforme esclarece Azevedo ${ }^{11}$, remete, segundo a tradição filosófico-jurídica, a uma qualificação que alguém goza; uma qualificação que representa uma função social, como, por exemplo, a reputação de um proprietário de grandes latifúndios dentro da sociedade burguesa do Iluminismo. O título, aliás, confere propriedade à posse legítima e, no caso dos direitos do homem do século XVIII, exprimiria a natureza racional do ser humano, os seus atributos caucasianos, os seus predicados masculinos e as suas qualidades essenciais e intrínsecas que o tornariam não só titular de um direito, mas também merecedor da virtude ou do dever moral.

Não podemos mais falar em merecimento ou mérito para justificar o fenômeno moral, como fazíamos na Idade Antiga, a partir de uma moralidade fundada em virtudes. Após o Iluminismo e o impacto que o discurso dos direitos humanos trouxe para a contemporaneidade, a análise da moral restou muito mais vinculada a uma concepção de igualdade entre os seres humanos que independe do mérito ou do fato de um homem se tornar merecedor, ou virtuoso, para, por exemplo, possuir um direito ou ser considerado moralmente um homem bom.

10 AZEVEDO, Marco Antônio Oliveira de. Rights as entitlements and rights as claims. Veritas, v. 55, n. 1, p. 166, jan./abr. 2010. Tradução nossa. Disponível em: http://revistaseletronicas.pucrs.br/ojs/index.php/veritas/article/view/7327. Acesso em: 22 jan. 2012. Versão original: view of rights as entitlements (AZEVEDO, Marco Antônio Oliveira de. Rights as entitlements and rights as claims. p. 166, grifos do autor.)

11 Azevedo aborda a visão dos direitos como títulos em contraste com a que visão que apresentaremos logo a seguir, que é a visão dos direitos como exigências, dos direitos que têm não somente right-holders (detentores), mas também duty-bearers (isto é, os destinatários da relação jurídica), embora lhes falte qualquer vínculo formal de título. Diz: "Assim, há pelo menos duas concepções diferentes sobre o tipo de relações legais (ou morais) que as quais são chamadas de direitos. Vou chamar a primeira visão dos direitos como títulos e a segunda visão dos direitos como exigências." (AZEVEDO, Marco Antônio Oliveira de. Rights as entitlements and rights as claims. p. 166, grifos do autor, tradução nossa) Versão original: Thus, there are at least two different conceptions about what kind of legal (or moral) relations we call rights. I shall call the first view of rights as entitlements and the second view of rights as claims. (AZEVEDO, Marco Antônio Oliveira de. Rights as entitlements and rights as claims. p. 166, grifos do autor.). 
Na modernidade, os direitos são feitos, pois, para um sujeito racional de direito, um sujeito formalmente igual a qualquer outro, mesmo que ironicamente situado dentro de um pequeno grupo que possui força para pleitear os seus direitos, o grupo dos homens e dos cidadãos, o grupo censitário dos brancos que pagam impostos porque são ricos proprietários de terras, com autoridade para reivindicar direitos e normatizar o comportamento dos outros. "Cartas e declarações de direitos têm sido tipicamente afirmações ou reafirmações dos direitos de algum grupo limitado."12, conforme afirma Baier. Continua:

Direitos têm sido geralmente para os privilegiados. Falar sobre leis, e os direitos que essas leis reconhecem e protegem, não garante por si só que o grupo de legisladores e detentores de direitos não será restrito a uma elite. Cartas de direitos têm sido geralmente proclamações dos direitos de algum grupo, barões, proprietários de terras, homens, brancos, não-estrangeiros. A "perspectiva de justiça" e o sentido legal que vem com ela são sombreados por seu passado patriarcal. ${ }^{13}$

Seguindo a lógica da modernidade, poderíamos até imaginar o título como uma "entidade metafísica" que alguém tem ou possui, como se fosse uma coisa do reino da natureza ou uma propriedade intrínseca à nossa natureza racional, como fizeram os doutrinadores dos direitos naturais. Diz Nickel: "Um título pode ser um forte conjunto de razões, enraizado na natureza dos seres humanos, para assegurar que um determinado bem está disponível para as pessoas." ${ }^{14}$.

À parte os delírios da razão humana, a análise da proposição "ter ou possuir um direito" revela, por si só, que há alguém, uma pessoa, um indivíduo, ou um grupo de indivíduos, que possuem ou têm uma permissão: "(...) os direitos possuem titulares, partes que possuem e exercem o direito." ${ }^{15}$. "Direitos pertencem a pessoas individuais, e são direitos sobre o que os indivíduos podem ter e fazer. ${ }^{16}$. Os direitos autorizam as pessoas, de modo que podemos identificar como uma importante característica da linguagem dos direitos, além da noção de título,

12 BAIER, Annette. Moral prejudices: essays on ethics. Tradução nossa. Cambride, Massachusettes: Harvard University Press, 1994, p. 226.

13 BAIER, Annette. Moral prejudices. p. 26.

14 NICKEL, James W. Making Sense of Human Rights. 2. ed. Malden: Blackwell, 2007. p. 30.

15 NICKEL, James W. Making Sense of Human Rights. p. 23.

16 BAIER, Annette. Moral prejudices. p. 236. 
a presença de um detentor ou beneficiário, de um sujeito que possui o direito. Afirma Peter Jones:

Direitos, necessariamente, têm possuidores. Não pode haver um direito sem que seja o direito de alguém. (...) O sinônimo mais próximo para 'direito' no idioma Inglês é 'título' e a posse de um direito pode ser concebida como a posse de um título. O que é distintivo sobre os sistemas legais ou morais que incorporam direitos é que eles investem pessoas com títulos. ${ }^{17}$

Embora a ênfase da dogmática tradicional dos direitos seja o portador do título, a proposição "X possui um direito" está, no mínimo, incompleta, no sentido de que $X$ só possui um direito se, e somente se, existir no outro polo da relação jurídica um destinatário para garantir ou cumprir o direito - do contrário, a frase não faz sentido.

O título ao qual nos referimos com a palavra "direito" possui um determinado alcance ou escopo; ele se dirige à outra parte definida, que é o seu destinatário. A relação jurídica constitui-se como o vínculo normativo que se estabelece entre deveres e direitos, entre portadores e destinatários, conforme afirma Nickel, ao abordar o caso dos direitos humanos:

(...) direitos humanos têm titulares (as pessoas que os possuem); destinatários (as partes atribuídas de deveres ou responsabilidade); e escopos que concentram-se sobre uma liberdade, proteção ou benefício. Além disso, os direitos são obrigatórios no sentido de que alguns comportamentos dos destinatários são requeridos ou proibidos. ${ }^{18}$

A proposição "X possui um direito" só ganha sentido lógico se for expressa da seguinte maneira: " $X$ possui um direito em relação a $Y$ " ou "relativamente a Y"; pois a figura do detentor do direito é claramente delimitada a partir da contraposição com a figura do destinatário desse direito, demonstrando que o significado do "direito" é entendido sob a ótica das obrigações, sejam obrigações morais, sociais ou jurídicas.

17 JONES, Peter. Rights: issues in political theory. Tradução nossa. Hampshire: Palgrave/ Macmillan Press, 1994. p. 36. Versão original: Rights necessarily have possessors. There cannot be a right without its being someone's right. (...) The nearest synonym to 'right' in the English language is 'entitlement' and the possession of a right may be conceived as the possession of a title. What is distinctive about legal or moral systems that incorporate rights is that they invest people with titles. (JONES, Peter. Rights. p. 36.)

18 NICKEL, James W. Making Sense of Human Rights. p. 9, grifos do autor. 
Os direitos se constituem como diretrizes normativas que visam determinar o comportamento dos outros e, nesse sentido, podemos trazer à tona a definição dos direitos de Leif Wenar, na Stanford Encyclopedia of Philosophy e destacar, assim como McCloskey, que o seu significado remonta sempre aos conceitos de autorização e permissão, representados na imagem metafísica do título ao portador.

Wenar ventila e resignifica a ideia de que os direitos seriam apenas títulos possuídos por detentores ao mostrar que os direitos têm também endereços e são sempre destinados a alguém. Diz Wenar:

Direitos são títulos para (não) realizar certas ações, ou para (não) estar em certos estados; ou títulos para os outros (não) realizarem certas ações ou (não) estarem em certos estados. ${ }^{19}$ (WENAR, 2011, sem número de página, tradução nossa)

Daí a afirmação de que um direito tem a função de normatizar o comportamento dos outros seres humanos, daqueles que se situam na posição de destinatários e, dessa maneira, se constitui como um direito em relação a, um direito para algo, talvez um direito contra alguém, um direito construído socialmente, seja no pequeno grupo, seja em sociedades maiores ou, até mesmo, na comunidade internacional.

Em posição para fazer exigências

Segundo a dogmática dos direitos, quando evocamos um direito, é porque estamos habilitados ou autorizados para tanto e, em razão disso, anunciamos a sua posse para normatizar o comportamento alheio, determiná-lo, direcionálo, para que o destinatário satisfaça a vontade ou o interesse do seu portador. Quando alguém diz que possui um direito, está dizendo que se encontra, ou julga encontrar-se, em uma posição para produzir exigências ou, mais do que isso, está dizendo que se encontra preparado ao direito, legitimado a reivindicálo e exigi-lo em razão do título que a lei lhe outorgou.

19 WENAR, Leif. RIGHTS. In: ZALTA, Edward N. (Ed.). The Stanford Encyclopedia of Philosophy. Fall 2011 Edition. Sem número de página. Tradução nossa. Disponível em: http://plato.stanford.edu/archives/fall2011/entries/rights/. Acesso em: 12 mar. 2012. Versão original: Rights are entitlements (not) to perform certain actions, or (not) to be in certain states; or entitlements that others (not) perform certain actions or (not) be in certain states. (WENAR, Leif in The Stanford Encyclopedia of Philosophy. Sem número de página.) 
Os direitos aparecem, então, nos usos da nossa linguagem por meio de asserções ou afirmações de direitos, quando apresentamos um título (legal) que certifica o seu portador e o autoriza a fazer algo ou a possuir alguma coisa, de modo que a sua titulação não só o nomeia a si como sujeito de direito como também lhe coloca em posição para exigir e reivindicar os seus direitos perante os outros, dando legitimidade ao seu exercício.

O "título" coloca seu portador na posição de exigente ou reivindicante, capacitando-o a impor deveres a seu destinatário; ele também confere liberdades a seu possuidor, na forma de privilégios, poderes e imunidades, que exige uma contrapartida negativa por parte de seu destinatário; ele coloca seu portador na condição múltipla de poder exigir, de poder fazer coisas sem ser impedido, ou de não sofrer o efeito de quaisquer exigências alheias, ou mesmo de ter poderes ou imunidades.

O "título" é a chave mais usual para compreender a definição dos direitos e das suas principais características, que dizem respeito às propriedades formais do direito e estão fortemente arraigadas ao princípio da legalidade. Contudo, as propriedades formais dos direitos já não conseguem explicar os usos que fazemos da palavra "direitos" na sociedade contemporânea.

Por certo, uma definição formal dos direitos, como a leitura dos direitos a partir da perspectiva do título ao portador, aplicamos ainda hoje a muitos ramos do direito privado, como, por exemplo, o Direito Empresarial ou o Civil quando tratam da posse e da propriedade. Ora, os direitos só são direitos porque outorgados por lei, sentenciados em decisão judicial ou concedidos em acordo lícito estabelecido entre duas partes. No entanto, no que tange aos direitos humanos, ou aos direitos reivindicados a partir das obrigações morais, essa definição não expressa, com discernimento e clareza, a complexidade que escondemos por trás do seu significado. Como, então, compreendê-los?

\section{DIREITOS EXIGIDOS SEM A POSSE DE UM TÍTULO}

O fato é que os direitos são afirmados mesmo sem a posse do título devido e, assim mesmo, por mais contraditório que isso pareça ser, falamos, ainda, em direitos 
que são usados linguisticamente para reivindicar e satisfazer exigências que não são necessariamente jurídicas. Asserções ou exigências por direitos são produzidas o tempo todo, por qualquer grupo de pessoas, e nem sempre essas exigências por direitos se explicam somente a partir da normatividade de um ordenamento jurídico, ou, propriamente, a partir de um título legal. Nem sempre uma pessoa está em posição legal para exigir direitos, ou mesmo para exigir seja lá o que for, mas, mesmo assim, ela pode expressar uma pretensão e, muitas vezes, requerer "direitos" que não estão previstos em uma moldura formal de normatividade.

Os direitos humanos e os direitos dos animais explicitam o caso de algumas asserções por direitos que não se constituíram ainda como título ou não estão necessariamente positivadas em um texto legal, evidenciando, assim, que a reivindicação desses direitos não se encontra necessariamente inserida em um sistema "jurídico" de obrigações. É bem verdade que, hoje em dia, os direitos humanos encontram-se, quase em sua totalidade, praticamente positivados e prescritos em algum tipo de lei.

Muitos Estados Soberanos já incorporaram a linguagem desses direitos em suas constituições e, para aqueles que resistem à dominação desses direitos, existem tratados e protocolos de direito internacional. No caso dos direitos dos animais, há leis municipais, estaduais, enfim, estatutos de conduta ou códigos de posturas que se dirigem à relação entre seres humanos e animais, de modo que só poderíamos falar nesses direitos porque eles se encontram enquadrados em alguma legislação específica.

Após a Segunda Guerra Mundial e durante a Guerra Fria, a linguagem dos direitos humanos se consolidou como um fenômeno cultural do mundo contemporâneo, conforme afirmou Rabossi (1990) ${ }^{20}$ e, em seguida, Rorty (1993) ${ }^{21}$. Não apenas acreditamos e falamos muito em direitos humanos, como também existe uma estrutura institucional por meio da ONU e de suas instâncias administrativas que 20 RABOSSI, Eduardo. La teoría de los derechos humanos naturalizada. Tradução de Matilde Vivancos Machimbarrena. Revista del Centro de Estudios Constitucionales, Madrid, n. 5, p.159-175, jan.-mar. 1990. Disponível em: <http://pt.scribd.com/doc/68557384/ Rabossi-La-Teoria-de-Los-Derechos-Humanos-Naturalizada>. Acesso em: 23 fev. 2012.

21 RORTY, Richard. Human rights, rationality and sentimentality. In: SHUTE, Stephen; HURLEY, Susan (Org.). On Human Rights: the 1993 Oxford Amnesty Lectures. New York: Basic, 1993. p. 111-134. 
estariam aptas a garantir a efetividade e a aplicação desses direitos. Podemos, inclusive, dizer que quase todos os direitos humanos são hoje direitos legais, porém, nem sempre foi assim e alguns deles ainda hoje carecem de positivação, embora já estejam em via de se concretizar e passar a existir juridicamente.

Não obstante esse fato no que tange a algumas exigências por direitos humanos, ainda não sabemos ao certo o que são, nem quais seriam esses direitos, como é o caso daquelas reivindicações por supostos direitos, como aborto, eutanásia, casamento homossexual, uso de drogas, dentre outros exemplos polêmicos, segundo os quais falamos em direitos que ainda não encontram respaldo jurídico e legal para serem classificados dessa maneira.

Como poderíamos, então, exigir direitos que não são propriamente direitos? Como poderíamos reivindicar um direito que a lei não o considera como tal? Essa é uma pergunta difícil, cuja resposta requer a comprovação de que os direitos, quando afirmados, possuem uma estrutura muito semelhante nos seus vários usos linguísticos, seja como direitos legais, seja como direitos extralegais. Eles se constituem basicamente como uma pretensão, a partir de exigências ou reivindicações por direitos.

Embora a herança liberal tenha motivado uma abordagem dos direitos centrada quase que exclusivamente na noção de um título que o sujeito de direito possuiria, não podemos fechar os olhos para a obrigação, nem deixarmos de entender os direitos como peças dentro da engrenagem das exigências e das obrigações mútuas - é justamente isso o que queremos destacar nesse trabalho, ao observarmos as limitações de uma abordagem dos direitos (em especial a dos direitos humanos) fundada na posse de um título e no vínculo que este ocasiona a beneficiários e destinatários.

\section{DISCERNINDO OS DIREITOS}

A complexidade da linguagem dos direitos não nos permite enxergar somente um tipo básico de direito sob o guarda-chuva do título e nem significados e funções isolados, mas, sim, um jogo de relações entre os vários sentidos que 
atribuímos à palavra "direito" ou à palavra "título"22. O direito é entendido a partir dessas relações, como um conjunto de vários tipos de direitos elementares; direitos, digamos assim, compostos por vários outros direitos inter-relacionados; direitos que se misturam, a partir da reunião das partes, para formar um grande conjunto de direitos - como, por exemplo, o mosaico dos direitos humanos.

Cabe, então, analisarmos essas partes como as peças de um grande quebracabeça, para, em seguida, reuni-las e mostrarmos como os direitos humanos podem ganhar algum sentido semântico e, o que é mais difícil, verificar se podemos trazer essas partes elementares e suas respectivas composições ao terreno da moralidade.

O primeiro jurista a identificar essas partes elementares que se escondem por trás da palavra "direito" foi Welsey Newcomb Hohfeld ${ }^{23}$ que, ao esmiuçar os usos do termo "direito", evidenciou as confusões conceituais e os mal-entendidos que envolvem não somente a linguagem dos juristas na lide diária dos tribunais, como também a dos filósofos que intentam uma fundamentação do direito, seja a partir da lógica, da política ou mesmo a partir da moralidade.

No caso dos direitos humanos e dos direitos dos animais, o problema tende a se tornar ainda mais grave, pois envolve não só juristas e filósofos, mas manifestantes e ativistas de todo o tipo de causa, espalhados por todo o mundo - cada um

22 Quando o sentido da palavra "direito" é posto em questão, encontramos, no mais das vezes, uma infinidade de sentidos que, em vez de esclarecer e destrinchar o conceito, mais revela que o sentido do "direito" não é unívoco, mas, por consequência, é dito e compreendido de muitas maneiras. Hohfeld compara a palavra "direito" a um camaleão colorido, tendo em vista que, de uma abordagem para outra, o direito ganha novas cores e é definido de múltiplas maneiras. Nesse sentido, afirma Hohfeld: "(...) para qualquer problema raciocinado de perto, seja legal ou não legal, palavras como camaleão-colorido são um perigo para aclarar o pensamento e elucidar a expressão." (HOHFELD, Wesley Newcomb. Fundamental legal conceptions as applied in judicial reasoning. Editado por David Campbell e Philip A. Thomas. Tradução nossa. Ashgate: Aldershot, 2001. p. 11.)

23 Wesley Newcomb Hohfeld, jurista estadunidense, é autor do livro Fundamental Legal Conceptions as Applied in Judicial Reasoning and Other Legal Essays (publicado em 1919), livro este composto por dois artigos escritos anteriormente para o Yale Law Journal. O primeiro deles, publicado em 1913, aborda os incidentes que se referem ao termo "direito", como as exigências e liberdades. O segundo, por sua vez, publicado em 1917, aborda e diferencia os direitos contidos nas obrigações pessoais daqueles que se referem a todo mundo, os direitos in rem. Conferir artigos: HOHFELD, Wesley Newcomb. 1913. Some fundamental legal conceptions as applied in judicial reasoning. The Yale Law Journal, v. 23, n. 16, p. 16-59. HOHFELD, Wesley Newcomb. 1917. Fundamental legal conceptions as applied in judicial reasoning. The Yale Law Journal, v. 26, p. 710-End. 
usando o mesmo termo em sentidos tão distintos. Conforme afirma Peter Jones, "(...) diferentes tipos de títulos mascaram o único termo 'direito'" ${ }^{\prime 24}$ e, nesse caso, a proposta de Hohfeld é interessante porque visa catalogar os usos que os juristas faziam na sua época da palavra "direito", de tal modo que podemos adotar um procedimento semelhante para descrever como nos referimos hoje aos direitos que evocamos a partir de uma perspectiva moral.

\section{UM JOGO DE RELAÇÕES}

Ao analisar a linguagem dos direitos, Hohfeld identifica algumas relações basilares que podemos inferir a partir dos usos que se faz diuturnamente da palavra "direito" e apresenta dois tipos de relações, a oposição e a correlatividade: "(...) ele considerou que, para cada tipo de direito, deve haver um termo correlativo descrevendo a posição da outra parte na relação." ${ }^{25}$ e identifica a recorrência dos operadores do direito a quatro sentidos básicos - as exigências, os privilégios, os poderes e as imunidades para o termo "direito" na expressão "ter ou possuir um direito em relação a alguém", seja por oposição, seja por correlação. Afirma Clayton:

Em sua análise clássica, Hohfeld identificou quatro diferentes tipos de relações jurídicas que podem ser descritas como títulos: uma exigência por direito, em que uma pessoa assere que tem uma exigência sobre outra; um direito de liberdade, que autoriza uma pessoa a fazer o que quiser por, por exemplo, a fumar; um poder, segundo o qual uma pessoa está habilitada ou empodeirada a, por exemplo, votar; e uma imunidade, que protege uma pessoa do poder de outra, como no caso de uma constituição foritificada que impede o legislador de substituir direitos constitucionais. ${ }^{26}$

Esses sentidos são "'os mais baixos denominadores comuns do Direito'"27. Diz Hohfeld: "(...) a linha mais promissora de procedimento parece consistir em expor todas as relações diferentes em um esquema de 'opostos' e 'correlativos', e os

24 JONES, Peter. Rights. p. 12.

25 JONES, Peter. Rights. p. 13.

26 CLAYTON, Richard; TOMLINSON, Hugh. The law of human rights. 2. ed. Tradução nossa. New York/Oxford: Oxford University Press, 2009. v. 1. p. 21, grifos do autor.

27 HOHFELD, Wesley Newcomb. Fundamental legal conceptions as applied in judicial reasoning. p. 30. 
procedimentos para exemplificar o seu alcance e aplicação em casos concretos." ${ }^{28}$. A tabela ${ }^{29}$ a seguir explicita esse esquema:

\begin{tabular}{|l|l|}
\hline OPOSTOS JURÍDICOS: & CORRELATIVOS JURÍDICOS: \\
\hline 1. Direito/Não direito; & 1. Direito/Dever; \\
2. Privilégio/Dever; & 2. Privilégio/Não direito; \\
3. Poder/Incapacidade; & 3. Poder/Sujeição; \\
4. Imunidade/Sujeição. & 4. Imunidade/Incapacidade. \\
\hline
\end{tabular}

Embora a preocupação deste jurista nunca tenha se destinado diretamente aos direitos humanos, senão apenas aos direitos legais e ao ordenamento jurídico, a sua tipologia ainda é relevante para a discussão que pretendemos estabelecer no presente trabalho, pois Hohfeld mergulha na engenharia burocrática da jurisprudência e destaca as confusões semânticas que se originam a partir dos vários sentidos que envolvem a palavra "direito", ressaltando que é justamente por meio desses significados que o "direito" pode ser compreendido como uma cadeia de relações conceituais.

\section{A ESTRUTURA FORMAL DOS DIREITOS: EXIGÊNCIAS E LIBERDADES}

Hohfeld mostra que o direito é entendido sob o pano de fundo das obrigações que são estabelecidas a partir de uma "exigência" ou de uma "liberdade"30. Para ele, os juristas não falam no direito sob uma perspectiva única e exclusiva, mas usam, porventura, alguns tipos básicos de direitos, como a liberdade, o poder e a imunidade. Diz Hohfeld:

28 HOHFELD, Wesley Newcomb. Fundamental legal conceptions as applied in judicial reasoning. p. 12.

29 No idioma inglês, as relações são denominadas do seguinte modo: JURAL OPPOSITES: 1. Right/no-right; 2. Privilege/Duty; 3. Power/Disability; 4. Immunity/Liability. JURAL CORRELATIVES: 1. Right/Duty; 2. Privilege/No-right; 3. Power/Liability; 4. Immunity/Disability. HOHFELD, Wesley Newcomb. Fundamental legal conceptions as applied in judicial reasoning. p. 12.

30 O termo "liberdade" pode gerar confusões e, em razão disso, o melhor seria optarmos pelo termo "privilégio", como o fez Hohfeld, embora isso não esteja tão claro assim em sua obra. A relação entre liberdade e privilégio marca a ideia de que alguém não está submetido ao dever de não fazer algo, o que não deixa de ser um "privilégio". 
(...) o termo 'direitos' tende a ser usado indiscriminadamente para cobrir o que num dado caso pode ser um privilégio, um poder, ou uma imunidade, ao invés de um direito em sentido estrito, e esta frouxidão de uso é ocasionalmente reconhecido pelas autoridades. ${ }^{31}$.

Juristas e autoridades usam o termo "direito"32 indistintamente para se referir a significados que, não raras vezes, são opostos e contraditórios entre si. De qualquer modo, podemos reduzi-los a alguns sentidos básicos, como afirma Mackie: "Direitos podem ser, formalmente, de vários tipos diferentes, mas a distinção mais básica é entre uma liberdade e uma exigência-direito." ${ }^{33}$. Do mesmo modo pensa Feinberg:

Autores de publicações sobre direito distinguem, comumente, "direitos strictu sensu", geralmente denominados direitos reivindicáveis, de "meras liberdades (lícitas)", chamadas frequentemente de privilégios e, algumas vezes, de licenças. ${ }^{34}$

Por um lado, estamos falando em "exigências por direito", quando o titular afirma possuir um direito e reivindica o seu cumprimento perante a outra parte, que, por seu turno, possui um dever, de modo que o direito é definido estritamente

31 HOHFELD, Wesley Newcomb. Fundamental legal conceptions as applied in judicial reasoning. p. 12. Versão original: (...) the term 'rights' tends to be used indiscriminately to cover what in a given case may be a privilege, a power, or an immunity, rather than a right in the strictest sense; and this looseness of usage is occasionally recognized by the authorities. (HOHFELD, Wesley Newcomb. Fundamental legal conceptions as applied in judicial reasoning. p. 12.)

32 Ver também: FEINBERG, Joel. The nature and value of rights. Journal of Value Inquiry, v. 4, p. 253, winter 1970. Disponível em: <http://www.law.georgetown.edu/faculty/lpw/ documents/FeinbergNatureandValueofRightsexcerpt.pdf>. Acesso em: 13 mar. 2012. Sobre a definição do verbete "direito" (no inglês, rights), afirma Henry Campbell Black no seu Law Dictionary: "Como um substantivo, e tomado em um sentido abstrato, significa justiça, correção ética, ou consonância com as regras da lei ou dos princípios da moral (...) Como um substantivo, e tomado em um sentido concreto, um poder, privilégio, faculdade, ou demanda, inerente a uma pessoa e incidente sobre a outra. (...) Um poder, privilégio ou imunidade garantida sob uma constituição, estatutos ou leis de decisão, ou exigido como resultado de um uso prolongado. (...) Em uma estreita significação, um interesse ou título em um objeto de propriedade;" (BLACK, Henry Campbell In: RIGHT. Black`s law dictionary: definitions of the terms and phrases of American and English jurisprudence, ancient and modern. 6. ed. Tradução nossa. St. Paul: West Publishing, 1990. p. 1323-24, grifos do autor.).

33 MACKIE, John Leslie. Ethics: inventing right and wrong. Tradução nossa. Harmondsworth: Penguin, 1990. p. 173. Versão original: Rights can be, formally, of several different sorts, but the most basic distinction is that between a liberty and a claim-right. (MACKIE, John Leslie. Ethics. p. 173)

34 FEINBERG, Joel. Filosofia social. p. 87. 
a partir da correlação com o dever. Por outro lado, estamos diante dos "direitos de liberdade", que são exercidos quando não há o impedimento físico de outrem, como é o caso do privilégio, do poder e da imunidade, segundo os quais o titular exerce o seu direito ao mesmo tempo em que não sofre a interferência e os obstáculos da outra parte da relação jurídica.

É bem verdade que a tipologia dos usos empregada por Hohfeld restringese às propriedades formais que se escondem por trás da palavra "direito", visto que, mesmo ao resguardar vários significados e se constituir, no fundo, como um termo polissêmico, o direito só pode ser entendido segundo os parâmetros da legalidade, pois, seguindo uma linguagem mais dogmática, só a legalidade poderia outorgar direitos.

\section{O ANTÍDOTO PARA A LEITURA FORMALISTA} DOS DIREITOS

O desafio, então, é deixarmos de lado as propriedades formais dos direitos - em especial a noção de titularidade, que pressupõe a posse do detentor em relação ao direito - para mergulharmos no universo da moralidade e o último passo do presente trabalho será justamente esse, de modo que o principal elemento a ser descartado é a noção de "título" ou "titulação" que o direito legal atribuiria ao seu possuidor - embora a maioria dos projetos fundacionalistas dos direitos humanos prefiram preservar o "título" e dizer que somos detentores de direitos humanos em virtude da nossa racionalidade, que, nesse sentido, nos autorizaria a possuir tais direitos não legais.

À parte a base metafísica dos direitos humanos, a proposta hohfeldiana abre a possibilidade para pensarmos os direitos para além da noção de "título" e de "titularidade", ressaltando que os direitos são, primordialmente, "exigências por direitos". Com base nesse retoque à análise de Hohfeld, o presente artigo aborda a natureza das exigências e das liberdades, bem como a estrutura formal do título, com o objetivo de enfatizar o seu fracasso para manipular e direcionar o comportamento humano com base na linguagem dos direitos humanos. 
Não obstante os limites da Jurisprudence ${ }^{35}$ de Hohfeld, o antídoto para a leitura formalista ${ }^{36}$ dos direitos reside nas "exigências" por direitos, a partir das quais os direitos vão sendo construídos, de modo que, ao anexar um direito elementar a outro, chegamos, ao final, ao nosso atual quadro de direitos humanos, compostos por direitos substancialmente básicos e primários, mas também por direitos compostos e construídos a partir da junção entre exigências, privilégios, poderes e imunidades.

Chegamos, enfim, a um sistema de obrigações que, na sua origem, é estritamente moral, mas que, ao se complexificar com a união dos direitos básicos, atinge as raias artificiais da legalidade e das obrigações jurídicas. Por causa disso, a redução da análise à noção de título deixa escapar uma infinidade de fenômenos nos quais a estrutura das exigências por direitos está presente, principalmente quando os direitos humanos são reivindicados e exigidos por pessoas que estão nas ruas, nos movimentos políticos e sociais, tais como os ativistas e manifestantes de direitos humanos.

Muitas vezes, quando alguém diz possuir direitos, ou quando se reivindica esses direitos contra terceiros, ou, ainda, quando se chega até mesmo a respeitálos e a entender a necessidade de se conviver a partir de exigências mínimas por direitos, não se está referindo a direitos outorgados por uma obrigação jurídica e nem àquilo que a tradição filosófica considera um direito, no sentido de possuir um direito.

Nem todos direitos humanos estão adstritos à dogmática jurídica e muitos deles são reivindicados mesmo sem a posse do título e em oposição a obrigações legais, de modo que não resta saída à nossa investigação a não ser abandonar a concepção tradicional de "ter um direito" como um título ao portador e, assim, evitar a via de tomá-lo como boas razões para interferir nas ações dos outros.

Deixando de lado a tipologia tradicional do "direito", podemos tomar alguns desses direitos simplesmente como "direitos-exigidos" (claim-right), ou como "exigências por direitos", exigências que são, não raras vezes, meras pretensões morais a algo ou mesmo pretensões por direitos. A partir dessas exigências, 35 A partir de uma tradução duvidosa, Jurisprudence significa o que para a Civil Law se chama Teoria Geral do Direito.

36 A leitura formalista dos direitos diz respeito à visão dos direitos como títulos. 
os direitos humanos se constituem por serem direitos compostos, formados a partir de outros direitos elementares, que envolvem poderes, imunidades, privilégios, dentre outros elementos que tornam a discussão desse tipo de direito cada vez mais complexa.

\section{CONSIDERAÇÕES FINAIS}

A observação do ato linguístico da reivindicação por direitos, como ocorre nos atos de fala segundo os quais o seu anunciante diz que ele próprio ou outra pessoa possui um direito, leva a investigação filosófica sobre a natureza dos direitos à conclusão de que os direitos podem existir mesmo fora de um ordenamento jurídico. As categorias formais dos direitos, assim como a própria interpretação dogmática da linguagem dos direitos, são, por certo, relevantes para a compreensão dos direitos legais. Porém, no que tange aos direitos exigidos a partir de obrigações morais, esse tipo de interpretação se mostra limitada e obsoleta, em completa desarmonia com o modo pelo qual o senso comum vem dando sentido aos direitos humanos.

Dessa maneira, a hipótese arrolada no início da presente pesquisa - que diz que alguns direitos (como os direitos humanos) são exigidos mesmo sem a posse de um título - nos leva a concluir que a linguagem dos direitos pode normatizar o comportamento humano mesmo sem a posse formal de um título. Com base em uma abordagem descritiva do ato de enunciação dos direitos, podemos inferir que os direitos humanos são exigências informais por direitos reivindicados mesmo quando não existe um título. São exigências que os seus reivindicantes chamam de direitos e que os outros - em especial o destinatário nem sempre o reconhecem como tal.

Essas exigências apontam para direitos e obrigações que são, no fundo, obrigações morais por excelência, obrigações que não dependem da esfera jurídica - o que nos leva a pensar em um tipo de direito que só ocorre no fenômeno moral, como alguns direitos humanos: o aborto, a eutanásia, o casamento homossexual, o uso permitido de drogas, dentre tantos outros "direitos" que 
conflitam com os direitos já estabelecidos como legais. São direitos paradoxais, que mais problematizam do que apontam soluções, que mais revelam a face obscura do ser humano largado à sua própria natureza do que propõem um edificante processo de libertação humana.

\section{REFERÊNCIAS}

AZEVEDO, Marco Antônio Oliveira de. Rights as entitlements and rights as claims. Veritas, v. 55, n. 1, p. 164-182, jan./abr. 2010. Disponível em: < http://revistaseletronicas.pucrs.br/ojs/ index.php/veritas/article/view/7327>. Acesso em: 22 jan. 2012.

BAIER, Annette. Moral prejudices: essays on ethics. Cambride, Massachusettes: Harvard University Press, 1994. 369p.

BENN, Stanley I. RIGHTS. In: EDWARDS, Paul (editor). Encyclopedia of Philosophy. 1. ed. New York: Macmillan, 1972. v. 7. p. 195-199.

BENTHAM, Jeremy. A fragment on government. Cambridge: Cambridge University Press, 1998. 128p.

BLACK, Henry Campbell In: RIGHT. Black`s law dictionary: definitions of the terms and phrases of American and English jurisprudence, ancient and modern. 6. ed. St. Paul: West Publishing, 1990. p. $1323-1324$.

CLAYTON, Richard; TOMLINSON, Hugh. The law of human rights. 2. ed. New York/Oxford: Oxford University Press, 2009. v. 1. 2193p.

FEINBERG, Joel. The nature and value of rights. Journal of Value Inquiry, v. 4, p. 243-257, winter 1970. Disponível em: <http://www.law.georgetown.edu/faculty/lpw/documents/ FeinbergNatureandValueofRightsexcerpt.pdf>. Acesso em: 13 mar. 2012.

FEINBERG, Joel. Filosofia social. Tradução de Alzira Soares da Rocha e Helena Maria Camacho. Rio de Janeiro: Zahar, 1974. 178p.

HART, Herbert Lionel Alphonsus. Definição e teoria na teoria do direito. In: Ensaios sobre teoria do direito e filosofia. Tradução de José Garcez Ghirardi e Lenita Maria Rimoli Esteves. Rio de Janeiro: Elsevier, 2010. Coleção Teoria e Filosofia do Direito. Ensaio 1. p. 23-52.

HART, Herbert Lionel Alphonsus. Definition and theory in jurisprudence. In: Essays in Jurisprudence and Philosophy. Oxford, Clarendon Press, 1983. p. 21-48. 
HOHFELD, Wesley Newcomb. 1913. Some fundamental legal conceptions as applied in judicial reasoning. The Yale Law Journal, v. 23, n. 16, p. 16-59.

HOHFELD, Wesley Newcomb. 1917. Fundamental legal conceptions as applied in judicial reasoning. The Yale Law Journal, v. 26, p. 710-End.

HOHFELD, Wesley Newcomb. Fundamental legal conceptions as applied in judicial reasoning. Editado por David Campbell e Philip A. Thomas. Ashgate: Aldershot, 2001. 112p. (Classical jurisprudence series).

JONES, Peter. Rights: issues in political theory. Hampshire: Palgrave/Macmillan Press, 1994. $258 \mathrm{p}$.

MACKIE, John Leslie. Ethics: inventing right and wrong. Harmondsworth: Penguin, 1990. 249p.

MCCLOSKEY, H. J. Rights. The Philosophical Quarterly, v. 15, n. 59, abr. 1965, p. 115-127. Disponível em: <http://www.jstor.org/stable/2218211>. Acesso em: 9 jun. 2012.

MCCLOSKEY, H. J. Rights: some conceptual issues. Australasian Journal of Philosophy, v. 54, n. 2, p. 99-115, ago. 1976. Disponível em: <http://www.tandfonline.com/doi/ abs/10.1080/00048407612341101>. Acesso em: 9 jun. 2012.

NICKEL, James W. Making Sense of Human Rights. 2. ed. Malden: Blackwell, 2007. 267p.

RABOSSI, Eduardo. La teoría de los derechos humanos naturalizada. Tradução de Matilde Vivancos Machimbarrena. Revista del Centro de Estudios Constitucionales, Madrid, n. 5, p.159-175, jan.-mar. 1990. Disponível em: <http://pt.scribd.com/doc/68557384/Rabossi-LaTeoria-de-Los-Derechos-Humanos-Naturalizada>. Acesso em: 23 fev. 2012.

RORTY, Richard. Human rights, rationality and sentimentality. In: SHUTE, Stephen; HURLEY, Susan (Org.). On Human Rights: the 1993 Oxford Amnesty Lectures. New York: Basic, 1993. p. 111-134.

WENAR, Leif. RIGHTS. In: ZALTA, Edward N. (Ed.). The Stanford Encyclopedia of Philosophy. Fall 2011 Edition. Disponível em: http://plato.stanford.edu/archives/fall2011/entries/rights/. Acesso em: 12 mar. 2012.

NOTA

1 HOHFELD, Wesley Newcomb. Fundamental legal conceptions as applied in judicial reasoning. p. 12. 